\title{
O FENÔMENO CÁRSTICO EM SÃO THOMÉ DAS LETRAS (MG) E A MINERAÇÃO: EVOLUÇÃO E DEGRADAÇÃO DE CAVERNAS EM QUARTZITO
}

\author{
THE KARST PHENOMENON IN SÃO THOMÉ DAS LETRAS \\ (MG) AND MINING: EVOLUTION AND DEGRADATION OF \\ QUARTZITIC CAVERNS
}

\author{
Roberto Marques Neto \\ Departamento de Geociências - Instituto de Ciências Humanas - Universidade Federal de Juiz de Fora - \\ Rua José Lourenço Kelmer, s/n - Campus Universitário - Bairro São Pedro - CEP: 36036-900 - Juiz de Fora/MG -
} e-mail: roberto.marques@ufjf.edu.br

\section{Informações sobre o Artigo}

Data de Recebimento:

25/05/2012

Data de Aprovação:

$30 / 04 / 2013$

\section{Palavras-chave:}

Cavernas em quartzito; São Thomé das Letras; Mineração; Carste.

\section{Keywords:}

Quartzite caverns; São Thomé das Letras; Mining; Karst.

\begin{abstract}
Resumo
Reconhecidamente, os processos de dissolução química não atacam exclusivamente rochas carbonáticas, podendo gerar morfologias cársticas também em rochas siliciclásticas, como arenitos e quartzitos. No Sul de Minas, as faixas quartzíticas remanescentes de dobramentos pré-cambrianos deram margem à formação de uma série de distritos espeleológicos entre os quais o de São Thomé das Letras que vem sofrendo impactos ambientais de maior vulto em função de predatória mineração de quartzito que ocorre no município. Em face a tal problemática, o presente artigo tem por objetivo discutir aspectos genéticos e evolutivos dos processos cársticos em questão e suas relações com a mineração.
\end{abstract}

\begin{abstract}
As admitted, the chemical dissolution processes doesn't attack solely carbonatic rocks, but can create karst morphologies over silicatic rocks as well as in sandstone and quartzites. In the South of Minas Gerais, the remaining quartzite strips of Precambian foldings gave rise to the formation of a series of speleologic districts among which São Thomé das Letras's have been suffering ambiental impacts of greater reachings due to the predatory quartzite mining that occurs there. In front of this problem, the present paper aims discussing genetic and evolving aspects of the karst processes in question and its relations with mining works.
\end{abstract}




\section{Introdução}

Algumas litologias podem ser francamente acometidas por processos de dissolução química, expandindo os domínios cársticos além das rochas carbonáticas. Outras rochas sedimentares como arenitos e folhelhos ou mesmo metamórficas como filitos e quartzitos podem suportar, não raro, a formação de feições geneticamente vinculadas a processos de dissolução dados pela ação da água nos planos de fraqueza, dando margem à geração de cavernas e depressões fechadas a partir de falhas e juntas.

A visada do presente artigo foca a discussão dos processos cársticos perpetrados em quartzitos, muito copiosos nas faixas de dobramentos pré-cambrianos que bordejam o Cráton do São Francisco. Cavernas de tamanho expressivo são verificadas nos quartzitos sacaroidais de Conceição do Ibitipoca, na Zona da Mata Mineira (SILVA, 2004). Um bom número de endocarstes também pode ser constatado na Serra de Carrancas e Chapada das Perdizes, entre os municípios de Carrancas e Minduri, localizados no Planalto do Alto Rio Grande, sul de Minas Gerais. Em Carrancas, além das cavernas em quartzito também é comum a ocorrência de algumas depressões fechadas em topos aplainados de crista monoclinal geneticamente vinculadas à dissolução. Em Minduri destacam-se feições ruiniformes semelhantes a torres nos patamares de cimeira aplainados, também herdadas de efeitos dissolutivos.

Avizinha-se mais para sul das áreas supramencionadas o município de São Thomé das Letras, conhecido pela ocorrência de quartzitos finos de potencialidade ornamental explorados a céu aberto, e veiculados no mercado sob a alcunha de "pedra São Thomé", com variações de colorações brancas, amarelas e róseas (predomínio da primeira) dada por contato brusco horizontal, vertical e lateral (FERNANDES, 2002). Os processos cársticos são marcantes nas cristas quartzíticas de São Thomé das Letras, onde se contam desde pequenos condutos até cavernas bem desenvolvidas, algumas delas perigosamente ameaçadas pela exploração predatória da litologia em lume. A gênese dessas feições e os impactos ambientais que as mesmas vêm padecendo em função da mineração constituem os dois pontos principais de discussão a encerrar os objetivos do presente artigo.

O município de São Thomé das Letras está na parte meridional de Minas Gerais (figura 1). Geomorfologicamente está inserido na região dos Planaltos do Alto Rio Grande (RADAMBRASIL, 1983), com padrões de formas em morros e morrotes diferencialmente dissecados e emoldurados em litologia gnáissica, tipicidade interrompida por cristas quartzíticas de orientação geral NE-SW e caráter assimétrico, apresentando front íngreme orientado para SE contrário ao mergulho das camadas metassedimentares e reverso suavemente inclinado para NW.

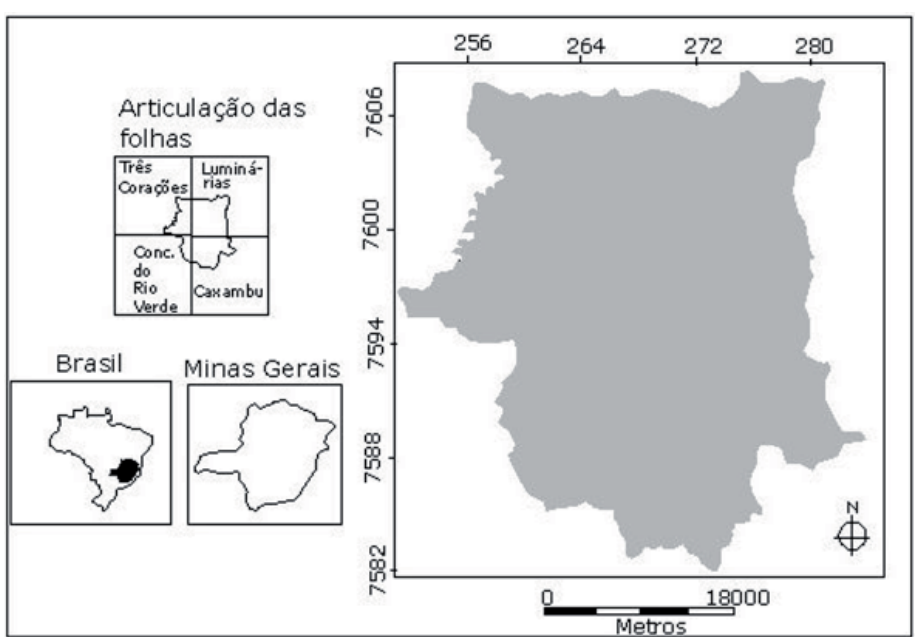

Figura 1 - Localização do município de São Thomé das Letras (MG).

\section{Procedimentos metodológicos}

Os levantamentos das formações cársticas foram avaliados diretamente em campo, empreendendo-se a representação de perfis das grutas do Carimbado e do Sobradinho, destacadamente relevantes em função de sua dimensão e de suas interações com a mineração e com o turismo. Utilizouse de trena de $5 \mathrm{~m}$ para a execução das medidas internas das cavernas em seus diferentes compartimentos, lançando mão do auxílio de lanterna e bússola em conformidade com as orientações de Auler \& Zogbi (2005). Os dados foram anotados em caderneta de campo e posteriormente transplantados em papel milimetrado vegetal divido em células quadráticas com dimensões de $1 \mathrm{~cm}$ x $1 \mathrm{~cm}$, onde foram traçados o perfil longitudinal da Gruta do Sobradinho e a planta da Gruta do Carimbado. Optou-se pela feitura do perfil da primeira caverna citada pelo fato daquela não apresentar ramificações e formação de labirintos, o que fez sugestivo esse tipo de representação, capaz de revelar as extensões dos compartimentos, a proporcionalidade entre os mesmos e a inclinação do conduto. Como a Gruta do Carimbado apresenta formação de salões e algumas ramificações, a representação em planta foi a mais eficaz para visualização dos padrões geométricos desse endocarste. Estas e as demais feições cársticas foram georreferenciadas em GPS Garmin, modelo Etrex.

As campanhas de campo também foram aproveitadas para georreferenciamento das áreas de mineração limítrofes a modelados cársticos, especificamente a Gruta do Carimbado, que entre as duas representadas é que se localiza no entorno de minas atualmente ativas. Com o auxílio de fotos aéreas, imagens orbitais (TM-Landsat-5) e levantamentos planialtimétricos, estabeleceu-se uma base de mapeamento na interface carste/mineração em escala $1 / 2500$ na qual foram plotadas: 1. As cavidades naturais; 2. As pilhas de estéril; 3. Drenagem e vias de acesso; 4. As direções preferenciais de 
escoamento superficial; 5. Os limites recomendáveis para conservação. Com tal sobreposição de atributos foi possível uma visualização espacial adequada e detalhada dos fatores de ameaça.

\section{Processos cársticos em São Thomé das Letras}

As cavernas e demais feições cársticas de São Thomé das Letras pertencem à Província Espeleológica Andrelândia, especificamente ao Distrito Espeleológico de São Thomé das Letras (CORRÊA NETO \& DUTRA, 1997). É composta por quartzitos micáceos finos, bandados em notável paralelismo e com mergulhos suaves em cristas monoclinais. Tais quartzitos redefinidos por Trouw et al (1980) e Trow (1982) no Grupo Carrancas, atualmente são consensualmente agrupados na Megassequência Andrelândia (HEILBRON et al. 2004). De acordo com estes autores ocorre em todos os domínios pertencentes ao terreno ocidental do Orógeno Ribeira, a sul e sudeste do Cráton do São Francisco (domínios autóctones), bem como nos terrenos alóctones (nappes) da porção sul do Orógeno Brasília, a sudoeste do Cráton do São Francisco. Correspondem, em outras palavras, aos metassedimentos depositados na margem passiva do cráton sanfranciscano metamorfisados em diferentes fases deformacionais durante a orogenia Brasiliana.

A elevada resistência das litologias quartzíticas ao ataque químico faz com que os sistemas de relevo emoldurados nessas rochas assumam a condição de altos estruturais, frequentemente resguardados sob o status de anomalias positivas do relevo. Contudo, o paralelismo preservado do ambiente deposicional de origem dá margem à penetração da água e, a reboque, de elementos ácidos agentes de dissolução. As camadas metassedimentares também são cortadas por densa rede de diáclases perpendiculares ao bandamento em distanciamento predominantemente métrico a decamétrico, e que também são frentes ativas de penetração da água, e, por isso, bastante exploradas pelo sistema radicular dos campos rupestres adaptados a este ambiente onde a retenção de umidade é dificultosa.

Esse padrão litoestrutural, associado à disponibilidade hídrica, vem favorecendo, pelo menos ao longo do Quaternário, os processos de carstificação. Tais processos podem, inclusive, remontar a tempos mais remotos do Neógeno, ainda que não se verifique a ocorrência de formas e depósitos paleocársticos que forneçam indícios plausíveis. Através da dissolução química a partir de uma linha ou plano de fraqueza é que se inicia a formação dos pequenos condutos, depressões e cavernas de São Thomé das Letras.

Pelas faixas quartzíticas ocorrem pequenas depressões fechadas, algumas morfologicamente similares à dolinas, outras que se assemelham a mini voçorocas onde ocorre alguma cobertura de alteração. Em ambos os casos fica bastante latente a solubilização do quartzito e formação de coberturas de areias quartzosas, bem como a existência de frentes preferenciais de intemperismo alinhadas às zonas de fraqueza que evoluem em caráter regressivo, tendendo a se estreitar com a elevação topográfica.

Condutos restritos ocorrem também em pontos diversos do município. Indubitavelmente, está entre os mais conhecidos e frequentados aquele localizado na área urbana, na região mais central da cidade. Além dessa manifestação, também é digna de nota a designada "pedra da taça", um pequeno conduto de apelo cênico, não propriamente por sua beleza, mas pela sua desoladora condição de testemunho das interessantes feições de dissolução que ocorrem nos relevos quartzíticos, atualmente remanescente entre as minas abertas.

As morfologias cársticas mais bem desenvolvidas em São Thomé das Letras são as grutas do Sobradinho, localizada na serra homônima, e a do Carimbado, localizada na vertente oeste da Serra de São Tomé.

A caracterização morfológica da Gruta do Sobradinho e a sua evolução já foram objeto de discussão (MARQUES NETO, 2008). Constitui uma caverna vadosa com aproximadamente $130 \mathrm{~m}$ de extensão que se abre em salão cuja entrada apresenta $9.5 \mathrm{~m}$ de altura por $6,7 \mathrm{~m}$ de largura que após perfazer extensão de $20 \mathrm{~m}$ dá lugar a mais cinco compartimentos estreitos que se intercalam em condutos e pequenos salões. O salão que marca a entrada da caverna contrasta em relação aos demais compartimentos, cujas passagens são facilmente averiguadas em campo, mas de difícil representação, uma vez que as medidas de altura e largura muito se assemelham a partir do terceiro compartimento. Tal fato fica latente pela visualização da figura 2 , que revela um perfil longitudinal plano-horizontal a suavemente inclinado.

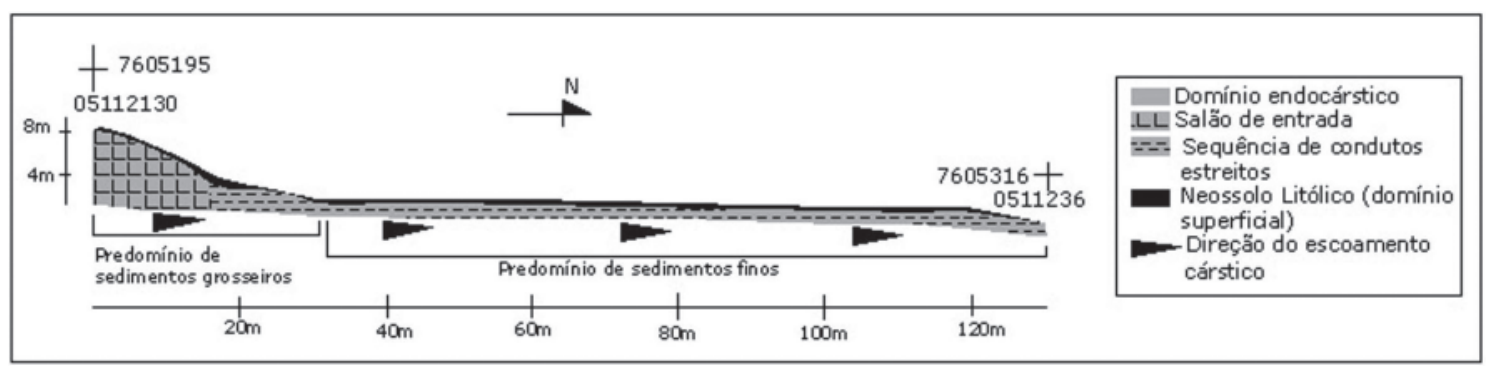

Figura 2 - Perfil longitudinal da Gruta do Sobradinho (São Thomé das Letras, MG). 
No salão da Gruta do Sobradinho se observa uma surgência hídrica que drena em condições subterrâneas até ser expelida da caverna. O assoalho, sobretudo ao longo do salão e do compartimento a ele diretamente conectado, é revestido por materiais detríticos, de granulometria diversa, em parte autóctones, vinculados à evolução da própria caverna, principalmente pelo desplacamento de lascas de quartzito do teto, e em parte transportados para o interior da cavidade de outros segmentos de vertente.

Fatores climáticos e tectono-estruturais são aventados na interpretação da gênese e evolução da Gruta do Sobradinho. A dinâmica epirogenética positiva reconhecida para os terrenos cristalinos da Serra da Mantiqueira e do Planalto do Alto Rio Grande, relacionada à atividade neotectônica intraplaca, vem aqui favorecendo uma reorganização e expansão remontante da drenagem nas falhas de empurrão reativadas, morfologicamente expressas pelas serras quartzíticas que aportam os processos cársticos. Ao que parece, as taxas de umidade vem sendo suficientes para garantir a evolução de muitas cabeceiras por processos químicos, da maneira que se vê numa série de linhas de aprofundamento por dissolução de largura e comprimento variável formadoras de uma coleção de depressões na Serra do Sobradinho, principalmente no entorno de sua gruta homônima. Essas frentes preferenciais de intemperismo tem se demonstrado importantes na evolução morfológica em relevos quartzíticos.

Foram levantadas algumas fases de evolução para a Gruta do Sobradinho, sequenciadas a seguir:

Primeira fase - Alteração da linha de fraqueza: Etapa inicial processada em condições climáticas úmidas, com taxas pluviométricas suficientes para engendrar umidade no sistema climático e possibilitar o avanço do intemperismo químico no quartzito.

Segunda fase - Abertura do conduto: A passagem da água oriunda das encostas à montante se encarregou da desobstrução do conduto, removendo as areias quartzosas produtos da alteração e garantindo seu alargamento.

Terceira fase - Desgaste mecânico: À medida que a altura do conduto aumenta, a força gravitacional vai acentuando sua interferência mediante o desprendimento do material alterado e sua inexorável queda, adicionando um componente mecânico na evolução da caverna; é possível que uma diminuição nas taxas pluviométricas durante o último estágio glacial no final do Pleistoceno possa ter desacelerado o processo de dissolução e favorecido o alargamento por ordem física, período no qual detritos mais grosseiros devem ter sido gerados.

Quarta fase - Retomada da dissolução e desobstrução do conduto: Ao final do último período glacial, a estabilização do regime climático atual fez novamente predominar os processos dissolutivos, que provavelmente não chegaram a ser completamente abortados. Os materiais clásticos foram progressivamente removidos em seu excesso, se concentrando atualmente apenas na entrada da caverna, onde se aleitam em sítio preferencial de acumulação que é nível de base local em relação ao segmento superior da encosta. Possíveis canais secundários foram desconectados e a drenagem se ajustou por coalescência interna em um único eixo. É dever frisar que o processo de evolução da drenagem subterrânea para um único eixo provavelmente acompanha fases precedentes a esta.

Processos de alteração de falhas e juntas ou ainda a ocorrência de condutos em vias de formação, pouco extensos e obstruídos por areias quartzosas, ocorrem em condições topográficas e litológicas similares às da Gruta do Sobradinho, dando pistas consideráveis de suas fases iniciais de evolução, que, como um todo, é bastante congruente com as sequências mais gerais previsíveis na evolução desse tipo de caverna. A ocorrência destes estágios iniciais também sinaliza que os processos cársticos são vigentes em tempos atuais, chegando a partilhar de forma substancial na evolução do relevo em rochas quartzíticas localizadas em áreas de clima tropical úmido ou estacional.

A Gruta do Carimbado, que fica no reverso da Serra de São Tomé, é mais extensa e de geometria mais complexa que a Gruta do Sobradinho, ainda que os processos evolutivos sejam semelhantes. Diferencialmente, verifica-se para a Gruta do Carimbado um abatimento que interrompeu sua continuidade, apresentando atualmente duas aberturas, a primeira delas, à montante, de menor extensão (pouco menos de 50m), e o segmento à jusante o mais extenso (aproximadamente $260 \mathrm{~m}$ ). Apresenta-se inclinada com alguns escalonamentos em perfil e dendrítico-meandrante em planta (figura 3). Na segunda abertura é possível constatar o aprofundamento do conduto que foi colmatado a se abrir vertente acima, mostrando que os dois segmentos já estiveram ligados. As duas entradas são dadas por salões com aspecto de dolina, em grande parte alargados por abatimentos, registrados pelos blocos de quartzito no assoalho da entrada.

A dissolução que engendrou a Gruta do Carimbado acometeu quartzitos micáceos, tendo as micas dado origem a níveis argilosos ao longo da frente de intemperismo. $\mathrm{O}$ curso d'água responsável pela dissolução que originou a gruta encontra-se atualmente desconectado da rede de drenagem superficial, e o seu paleocanal colmatado é ainda bastante visível. No entanto, conforme o conduto vadoso se aprofunda, o lençol freático começa a aflorar podendo mesmo estabelecer um canal efêmero e possíveis inundações das partes baixas durante as chuvas, uma vez que o escoamento superficial e mesmo pequenas linhas de escoamento concentrado atingem a caverna. Diferentemente da Gruta do Sobradinho, esta não apresenta abertura de saída, estreitando-se em sua parte final. 


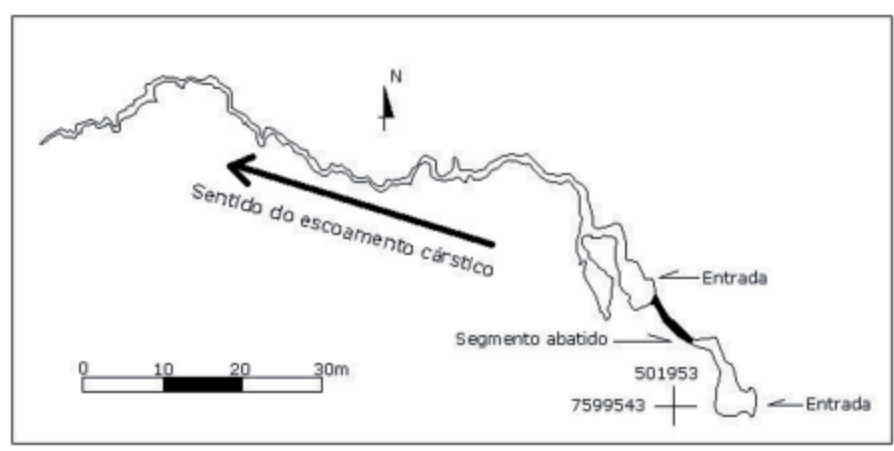

Figura 3 - Representação em planta da Gruta do Carimbado

\section{A mineração}

No município de São Thomé das Letras tem lugar a mais depredatória extração de quartzito a céu aberto entre todos os outros centros produtores de Minas Gerais (Luminárias, Alpinópolis, Diamantina). O processo de lavra ocorre na vertente oeste da Serra de São Tomé, profundamente desfigurada de sua morfologia original em função da exploração do minério, que engendrou na área uma morfologia, na acepção de Rodrigues (2005), essencialmente antropogênica.

A prática exploratória deu margem a uma alteração nas cotas altimétricas à medida que vem rebaixando o relevo em concomitância a retirada sucessiva das lajes conforme o paralelismo das camadas metassedimentares, que chega a aprofundar seções de encosta em mais de uma centena de metros em crateras vertiginosas. Os declives ora são aumentados por conta dos taludes que ficam expostos, ora suavizados nos segmentos aplainados sobre os quais são dispostas as imensas pilhas de estéril.

De maneira despudorada as frentes de lavra consomem as áreas de preservação permanente que deveriam ser mantidas nas linhas de cumeada a partir do terço superior da vertente, bem como desbastam as matas galeria que, envolvendo os cursos d'água, se diferenciam dos campos rupestres, estes em grande parte desfigurados pela mineração e destituídos de sua diversidade. Sobre os singulares campos rupestres que medram nos quartzitos são acomodados os rejeitos, quando não são removidos para a abertura das lavras.

Formata-se então no reverso da Serra de São Tomé uma paisagem de aspecto esbranquiçado cuja superfície é coberta pelo estéril de variada ordem granulométrica que não é acomodado nas pilhas, estas se intercalando com crateras de variado tamanho e avançando à montante nas proximidades das surgências hídricas.
Os fluxos superficiais encontram-se profundamente desorganizados, com o escoamento concentrado dando lugar, em parte, ao escoamento difuso, que perpassa de forma caótica pelas rugosidades impostas pela atividade minerária, carregando as areias quartzosas e materiais de maior tamanho para fora da área de exploração, definindo-se uma área de influência direta significativamente afetada.

Nas áreas de influência direta da mineração os cursos d'água encontram-se excessivamente entulhados, revestidos continuamente por grânulos, seixos e matacões, além de areias quartzosas em profusão, formando sucessivos bancos que aumentam seu espaçamento com o distanciamento da área de exploração. O caráter aberrante da carga de fundo produto de contribuição incompatível com a competência de transporte destes cursos d'água de largura e extensão moderadas vem repercutindo em morfodinâmica aguda expressa pela erosão lateral acelerada e alargamento pronunciado dos cursos d'água. Christofoletti (1981) chama a atenção para o fato de que para os rios incumbidos de transportar carga de elevada ordem granulométrica a forma mais alargada do que profunda é a mais adequada ao seu perfil de equilíbrio. Dessa forma, os cursos d'água afetados na área de influência da mineração vão tendendo em alguns pontos a anastomose, solapando as margens e espraiando os materiais gravitacionalmente transportados em seu leito alargado. O processo de solapamento acaba, em alguns casos, afetando a vegetação ripária, sendo que em alguns pontos a sua remoção e tombamento são inexoráveis.

A mineração é um forte fator de ameaça à Gruta do Carimbado, dada a sua proximidade com as frentes de lavra e, sobretudo, com as pilhas de estéril, que avançam em direção à cavidade transgredindo os espaços protegidos por lei. Machado (2013) cita o art. $1^{\circ}$ do Decreto 99.556 de $1 / 10 / 1990$, que versa taxativamente em prol da proteção destes ambientes: "As cavidades naturais subterrâneas existentes no território nacional constituem patrimônio cultural brasileiro e, como tal, serão preservadas e conservadas de modo a permitir estudos e pesquisas de ordem técnico-científica, bem como as atividades de cunho espeleológico, étnico-cultural, turístico, recreativo e educativo". Na contramão, o Decreto ${ }^{\circ} 6640 / 2008$ prevê a possibilidade do exercício minerário em cavidades naturais subterrâneas de menor valor ambiental; ficam ainda em aberto, entretanto, os critérios definidores dos valores ecológicos, culturais e históricos de uma expressão endocárstica. 
Constitui fator negativo para a proteção da Gruta do Carimbado o fato desta se encontrar em terras particulares exploradas por empresa de mineração (figura 4). O material estéril transportado no domínio das vertentes se acomoda nas dolinas de abatimento que configuram as duas cavidades de abertura do conduto. Os muros de contenção de rejeito posicionados à montante não possuem altura e continuidade suficiente para dar conta do pleno represamento do rejeito, que em grande parte transpõe as barreiras e se projeta em direção aos cursos d'água e outros sítios de acumulação, entre os quais a gruta em questão é opção.

Pelo menos até o presente momento, uma sucessão de pilhas se encadeia a partir de uma distância inferior a $50 \mathrm{~m}$ da cavidade ao longo da vertente na qual a mesma se desenvolve, sendo aí a principal área fonte dos materiais que vem entulhando a caverna.

São comuns em São Thomé das Letras problemas relacionados a trincas e rachaduras em paredes de residências, comprovadamente vinculados com as explosões por dinamite que ocorrem duas vezes ao dia. É provável que o uso do explosivo também exerça efeitos na estrutura. Vem sendo observado o desenvolvimento de rejeito centimétrico em junta que intercepta o teto da Gruta do Carimbado perpendicular à direção do acamamento, sugestivamente provocado pelas explosões. Fica latente que o teto está cedendo, e que a queda de placas de quartzito é iminente, o que incrementa ainda mais a fragilidade natural desses ambientes.

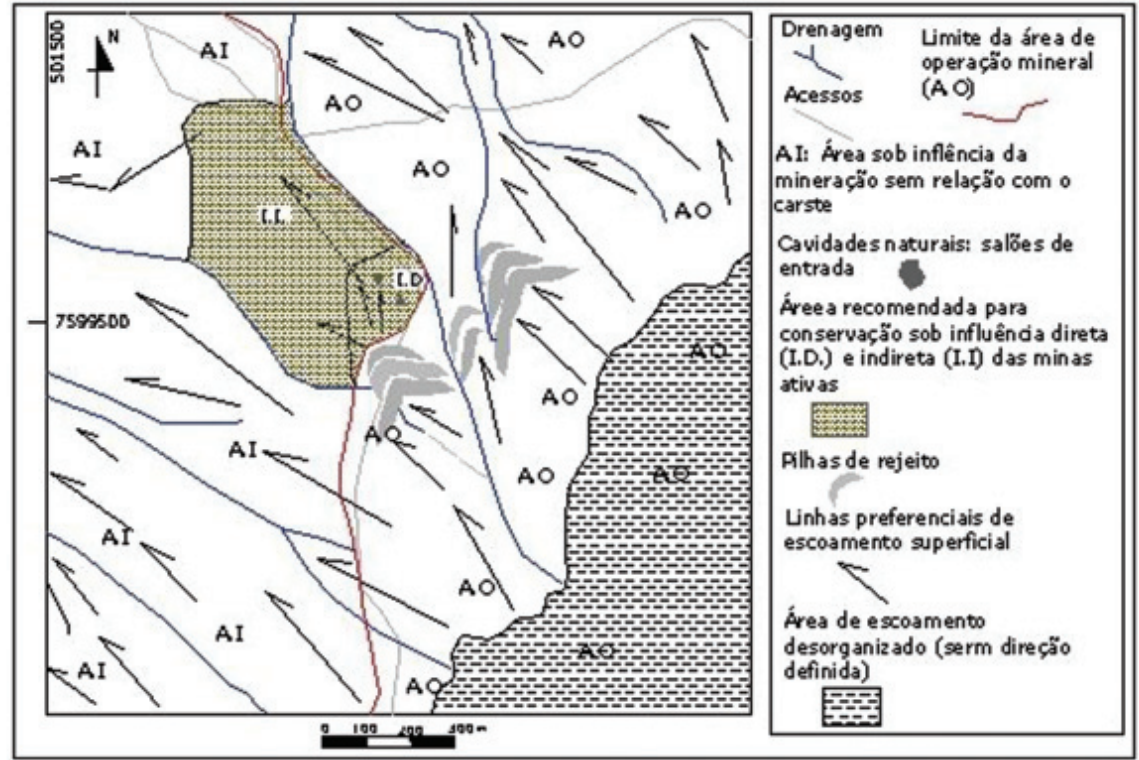

Figura 4 - Esquematização do entorno da Gruta do Carimbado e suas relações com a mineração.

Não é apenas a mineração, é dever frisar, que constitui fator de ameaça e agente de impacto para as formações cársticas em São Thomé das Letras. Indubitavelmente a atividade turística também não vem sendo levada a efeito em congruência com a capacidade de suporte desses ambientes. Tanto na Gruta do Carimbado como na do Sobradinho as pichações nas paredes, o descarte de resíduos sólidos e mesmo pequenos focos erosivos de pisoteio excessivo na entrada das cavernas são comuns.

Entre outros problemas que emergem da relação aparentemente excludente entre mineração e conservação dos recursos naturais em São Thomé das Letras, os impactos ocasionados nos sistemas cársticos são apenas uma nuance. Nas áreas de exploração os impactos são profundos em todo o conjunto de encostas, no substrato e coberturas associadas, na drenagem, na vegetação e na fauna, instaurando-se um quadro de degradação strictu sensu que padece da falta de medidas eficazes de controle e mitigação.

A figura 5 ilustra representativamente algumas formas e processos cársticos vigentes em São Thomé das Letras, e a figura 6 se encarrega de dimensionar as ações transformadoras engendradas pela mineração à montante das cavidades. 

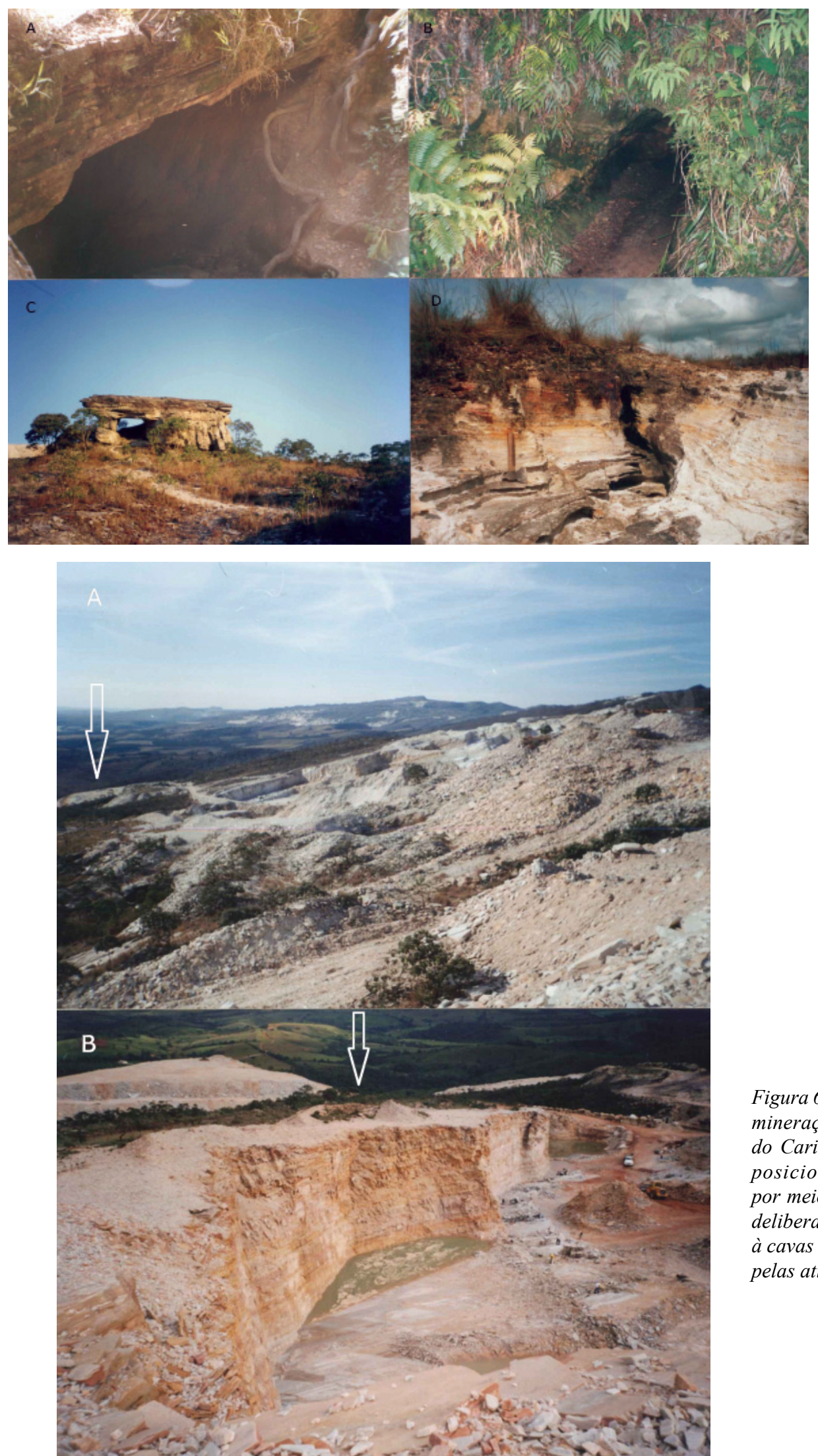

Figura 5 - Exemplos de morfologias e processos cársticos em São Thomé das Letras: A) Dolina de abatimento marcando a entrada superior da Gruta do Carimbado; B) Parte final da cavidade da Gruta do Sobradinho, com fluxo hídrico permanente; $C$ ) "Pedra da taça" - conduto formado por dissolução isolado entre as lavras abertas; D) Processo de dissolução no quartzito formando pequenas depressões a partir de planos de fraqueza.
Figura 6-Impactos ambientais da mineração à montante da Gruta do Carimbado com indicação do posicionamento das cavidades por meio das setas: A)Disposição deliberada do rejeito intercalada à cavas abertas; B) Talude gerado pelas atividades de lavra. 


\section{Considerações finais}

Os processos cársticos ocorrentes em São Thomé das Letras são, em grande medida, similares ao de outras províncias de litologia quartzítica no sul de Minas Gerais. Caracterizam-se pela formação de condutos estreitos e de extensão restrita com alguns sistemas mais bem desenvolvidos, destacadamente aqueles colocados em discussão, além de pequenas dolinas de abatimento e depressões fechadas geradas por dissolução. Coexistem feições mais desenvolvidas, de formação mais antiga, inclusive feições paleocársticas, e feições jovens em franca evolução representativas dos estágios iniciais de formação de condutos e cavernas. Faz-se então sugestivo que os processos de dissolução ocorreram durante todo o Quaternário (ou mesmo em tempos mais remotos do Cenozoico) - a se admitir provável desaceleração nas fases glaciais menos úmidas - e que tal ocorrência vem se dando em fortes similaridades, uma vez que os processos de dissolução são latentes e se dão sobre o mesmo contexto litoestrutural.

As feições cársticas de maior desenvolvimento em São Thomé das Letras são bastante visadas para o turismo, além dos impactos da mineração que afetam enfaticamente a Gruta do Sobradinho. Considerando o aspecto intensivo e mal planejado do turismo e a natureza depredatória da mineração, tem-se uma convergência de forças que atribui à área como a mais ameaçada e impactada entre os demais distritos espeleológicos da província na qual se insere.

O avanço das frentes de lavra é francamente justificado pelo decreto de 2008, uma vez que não são verificados espeleotemas (exceção feita a alguns microtravertinos) de monta na Gruta do Carimbado, tampouco registros arqueológicos e paleontológicos que fariam por definir a cavidade como de importância elevada. Por outro lado, não se trata aqui de um domínio de rochas carbonáticas com concentrações de calcário passível de ser aproveitado na agricultura ou siderurgia; se por um lado não se conjugam elementos que podem definir fortemente uma relevância ambiental, por outro lado o minério visado também não se apresenta como estratégico para a produção de alimentos ou para o setor produtivo. Em outras palavras, os benefícios econômicos oriundos de uma possível transgressão das atuais minas ativas ao domínio cárstico beneficiaria, não mais que isso, os poucos proprietários que atualmente exploram a área em caráter fortemente impactante.

\section{Referências bibliográficas}

AULER, A.; ZOGBI, L. Espeleologia: noções básicas. São Paulo: Redespeleo Brasil, 2005. 103p.

CORRÊA NETO, A. T.; DUTRA, G. M. A Província Espeleológica Quartzítica Andrelândia, Sudeste de Minas Gerais. In: XXIX CONGRESSO BRASILEIRO DE ESPELEOLOGIA. Anais... Ouro Preto, 1997.

CHRISTOFOLETTI, A. Geomorfologia fluvial. São Paulo: Edgard Blücher, 1981. 313p.

FERNANDES, T. M. G. Caracterização petrográfica, química e tecnológica do Centro Produtor de São Thomé das Letras no sudoeste do estado de Minas Gerais. Tese (Doutorado em Geologia Regional). Instituto de Geociências e Ciências Exatas, Universidade Estadual Paulista. Rio Claro, 2002.

HEILBRON, M.; PEDROSA-SOARES, A. C.; CAMPOS NETO, M. C.; SILVA, L. C.; TROUW, R. A. J.; JANASI, V. A. Província Mantiqueira. In: MANTESSO NETO, V. et al. (Org.) Geologia do continente Sul-americano: evolução da obra de Fernando Flávio Marques de Almeida. São Paulo: Beca, 2004. 647p.

MACHADO, P. A. L. Direito ambiental brasileiro. São Paulo: Malheiros Editores, 2013. 1311p.

MARQUES NETO, R. Evolução de caverna em quartzito e processos cársticos em São Thomé das Letras - MG: contribuição ao estudo de sistemas cársticos em rochas silicáticas. Geosul, Florianópolis, v. 23, n. 5, p. 105-121, 2008.

MINISTÉRIO DAS MINAS E ENERGIA. Projeto Radambrasil. Folha SF-23 - Vitória/Rio de Janeiro. Rio de Janeiro, 1983.

RODRIGUES, C. Morfologia original e morfologia antropogênica na definição de unidades espaciais de planejamento urbano: um exemplo da metrópole paulista. Revista do Departamento de Geografia, São Paulo, USP, v. 17, p. 101-111, 2005.

SILVA, S. M. Carstificação em rochas siliciclásticas: estudo de caso na Serra do Ibitipoca, Minas Gerais. 2004. 142p. Dissertação de Mestrado. Instituto de Geociências, Universidade Federal de Minas Gerais.

TROUW, R. A. J. Novos Dados sobre os Grupos São João Del Rey, Carrancas e Andrelândia. IN: II SIMPÓSIO DE GEOLOGIA DE MINAS GERAIS.(Anais) Belo Horizonte, 1983. p. 467-477

; RIBEIRO, A.; PACIULLO, F. V. P. Evolução Estrutural e Metamórfica de uma Área a Sudeste de LavrasMinas Gerais. IN: XXXI CONGRESSO BRASILEIRO DE GEOLOGIA. (Anais). Vol. 5. Santa Catarina, 1980. p. 2773-2784. 